\title{
Development and Application of the Power Plant Real-Time Temperature and Stress Monitoring System
}

\author{
Piotr Duda \\ Cracow University of Technology, Institute of Thermal Power Engineering, Al. Jana Pawła II 37, 31-864 Kraków, Poland \\ Correspondence should be addressed to Piotr Duda; pduda@mech.pk.edu.pl
}

Received 25 July 2017; Accepted 24 October 2017; Published 20 November 2017

Academic Editor: Keith E. Holbert

Copyright (C) 2017 Piotr Duda. This is an open access article distributed under the Creative Commons Attribution License, which permits unrestricted use, distribution, and reproduction in any medium, provided the original work is properly cited.

\begin{abstract}
The paper presents a method of temperature and stress estimation in pressure components of conventional or nuclear power plants. The proposed algorithm can be applied without the information concerning the thermal boundary condition on the component inner surfaces and it is fast enough to be applied in an online mode. The solution is possible thanks to "measured" temperature histories determined in easily accessible points located on the component outer surface. The presented model has been recently verified analytically, numerically, and experimentally. The proposed algorithm was used to calculate the transient temperature and stress distribution in the outlet header of a steam reheater and the results indicate that the component lower part is loaded the most, but allowable stresses are not exceeded. If the presented heating process was shortened, the calculated stresses would exceed the allowable values. Monitoring the boiler thermal and strength operating conditions makes it possible to identify dangerous loads of the power boiler pressure elements during transient-state operations. The presented method for controlling thermal and pressurerelated stresses is suitable for nuclear power plants because it does not require drilling holes for sensors in the pressure element walls.
\end{abstract}

\section{Introduction}

The behaviour of components of conventional or nuclear power plants has been investigated in numerous research projects [1]. During their operation, high stresses occur in thick-walled pressure elements. The operation cyclic character resulting from the cooling and heating of pressure elements causes the low-cycle fatigue phenomenon, which may lead to cracks. As power plants become older engineers need screening criteria to eliminate the risk of thermal fatigue. A number of programs have been launched to develop fatigue monitoring systems for the nuclear power plant components $[2,3]$. The use of monitoring systems has a significant impact on the remnant life prediction, highlighting hot zones in the boiler and the influence of modified operations on safe extension of the plant life [4]. The control system quality depends on the accuracy of stress calculations in selected elements of the power unit. The offline method of thermal stress evaluation by using the fluidstructure interaction in the piping system $T$-connections is presented in [5]. The whole area where the fluid is contained has to be discretized. Then the mass, momentum, and energy balance equations have to be written. Depending on the flow nature, it may also be necessary to introduce a suitable turbulence model. The calculations are more difficult in the case of two-phase flows that involve boiling or condensation processes. Green's function method with consideration of temperature-dependent material properties is shown in [6]. The main disadvantage of this method is the need to find the heat transfer coefficient. Another way to determine the distribution of temperatures and stresses is to solve the inverse heat conduction problem in the device under analysis. Inverse methods enable determination of the entire timeand space-dependent temperature distribution in an element based on measured temperature histories in selected spatial points $[7,8]$. The temperature distribution reconstructed in this manner makes it possible to calculate stresses in the analysed elements as accurately as possible [9].

The aim of this work is to present an online temperature and stress monitoring method. The commercial computational software, which is available on the market today, does not make it possible to solve the problem under 


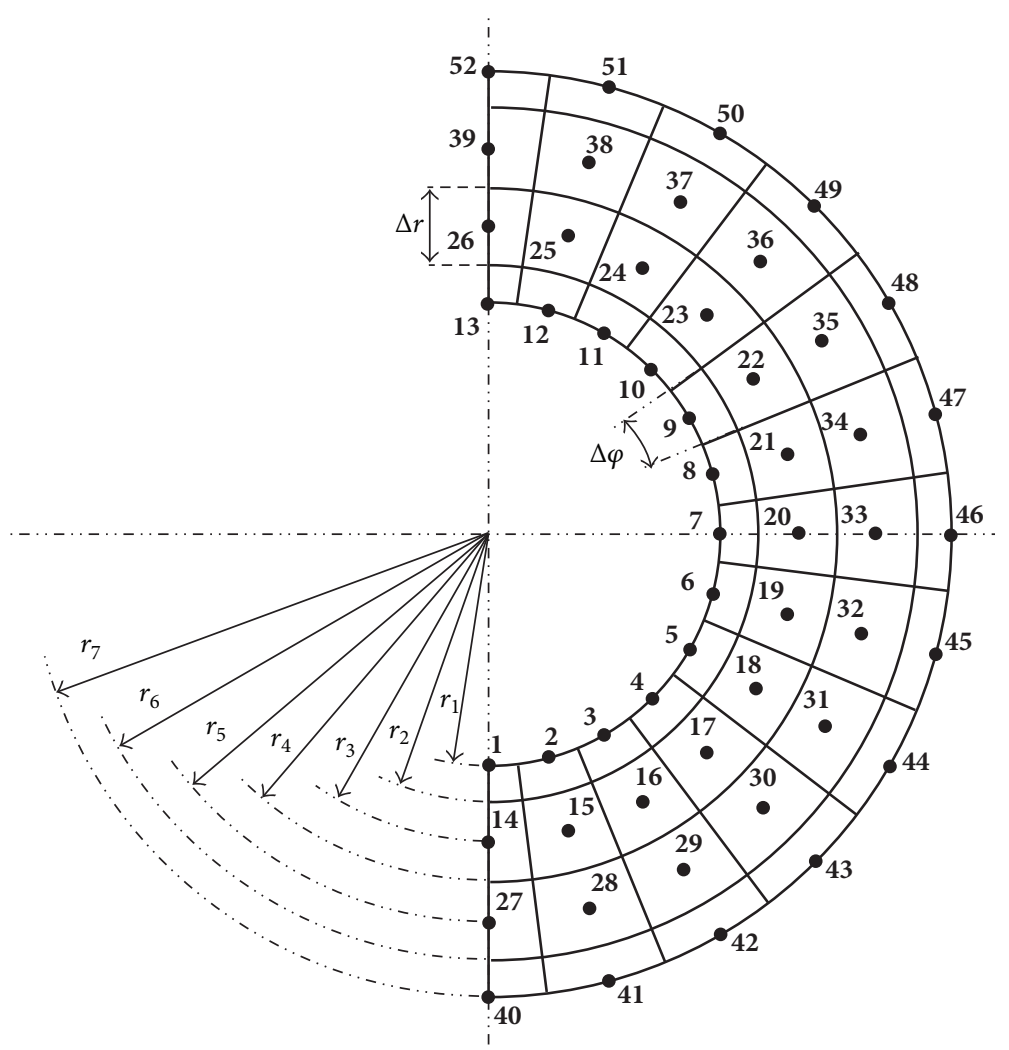

FIGURE 1: Division of a cylindrical component cross-section into control volumes.

consideration in an online mode because thermal boundary conditions are not defined on the monitored component inner surfaces. The proposed method has already been tested on a laboratory stand [9]. This paper presents the application of the proposed algorithm for the calculation of the transientstate temperature and stress distribution in the outlet header of a power plant steam reheater. The presented method for controlling thermal and pressure-related stresses is suitable for nuclear power plants because it does not require drilling holes for sensors in the pressure element walls.

\section{Formulation of the Method}

The equation governing the transient-state heat conduction problem has the following form:

$$
c(T) \rho(T) \frac{\partial T}{\partial t}=-\nabla \cdot \mathbf{q}
$$

where $\mathbf{q}$ is the heat flux vector. Fourier's law for an isotropic material takes the following form:

$$
\mathbf{q}=-k \nabla T
$$

All material properties ( $c$ : specific heat, $\rho$ : density, and $k$ : thermal conductivity) are assumed as known functions of temperature. The control volume finite element method is used [10]. Equation (1) is integrated over general control volume $V$ with bounding surface $S$ :

$$
\int_{V} c(T) \rho(T) \frac{\partial T}{\partial t} d V=-\int_{V} \nabla \cdot \mathbf{q} d V
$$

By applying the mean value theorem for integrals on the left and the divergence theorem on the right, the following equation is obtained:

$$
V c(\bar{T}) \rho(\bar{T}) \frac{d \bar{T}}{d t}=-\oint_{S} \mathbf{q} \cdot \mathbf{n} d S,
$$

where the bar indicates an average value in volume $V$ and $\mathbf{n}$ is a normal unit surface vector directed to the outside of the control volume.

If temperature does not vary in a cylindrical component along the generatrix but changes along the circumference and on the wall thickness, the unsteady-state temperature distribution is two-dimensional $T(r, \phi, t)$.

For such a problem, the analysis can be carried out only for a cross-section as presented in Figure 1. The cross-section is divided into control volumes. Assuming that the component outer surface is perfectly insulated and an unknown boundary condition occurs on the inner surface, the inverse problem may be solved starting with a heat balance equation for the control volume associated with node $i=40$. 
The heat balance equation (4) for node $i=40$ has the following form:

$$
\begin{aligned}
& \frac{d T_{i}}{d t}=\frac{4 a_{i}}{\left(r_{7}^{2}-r_{6}^{2}\right) \cdot \Delta \varphi}\left[\frac{k_{i+1}+k_{i}}{2 k_{i}} \cdot \frac{0.5 \cdot \Delta r}{r_{7} \cdot \Delta \varphi}\left(T_{i+1}-T_{i}\right)\right. \\
& \left.+\frac{k_{i-13}+k_{i}}{2 k_{i}} \cdot \frac{r_{6} \cdot 0.5 \cdot \Delta \varphi}{\Delta r}\left(T_{i-13}-T_{i}\right)\right],
\end{aligned}
$$

where $i=40, k_{i}=k\left(T_{i}\right), c_{i}=c\left(T_{i}\right), a_{i}=k_{i} /\left(c_{i} \cdot \rho_{i}\right)$.

Heat balance equations for control volumes $i=41-51$ are expressed as follows:

$$
\begin{aligned}
& \frac{d T_{i}}{d t}=\frac{2 a_{i}}{\left(r_{7}^{2}-r_{6}^{2}\right) \cdot \Delta \varphi}\left[\frac{k_{i-1}+k_{i}}{2 k_{i}} \cdot \frac{0.5 \cdot \Delta r}{r_{7} \cdot \Delta \varphi}\left(T_{i-1}-T_{i}\right)\right. \\
& +\frac{k_{i-13}+k_{i}}{2 k_{i}} \cdot \frac{r_{6} \cdot \Delta \varphi}{\Delta r}\left(T_{i-13}-T_{i}\right)+\frac{k_{i+1}+k_{i}}{2 k_{i}} \\
& \left.\quad \cdot \frac{0.5 \cdot \Delta r}{r_{7} \cdot \Delta \varphi}\left(T_{i+1}-T_{i}\right)\right]
\end{aligned}
$$

and for volume $i=52$ the following can be written:

$$
\begin{aligned}
& \frac{d T_{i}}{d t}=\frac{4 a_{i}}{\left(r_{7}^{2}-r_{6}^{2}\right) \cdot \Delta \varphi}\left[\frac{k_{i-1}+k_{i}}{2 k_{i}} \cdot \frac{0.5 \cdot \Delta r}{r_{7} \cdot \Delta \varphi}\left(T_{i-1}-T_{i}\right)\right. \\
& \left.+\frac{k_{i-13}+k_{i}}{2 k_{i}} \cdot \frac{r_{6} \cdot 0.5 \cdot \Delta \varphi}{\Delta r}\left(T_{i-13}-T_{i}\right)\right] .
\end{aligned}
$$

Temperature histories in nodes 27-39 can be obtained from 13 equations (5)-(7) based on the T40-T52 measured data.

If the material properties $c, \rho$, and $k$ are temperaturedependent, the system of (5)-(7) can be solved iteratively. At first, temperature unknowns are assumed as

$$
T_{k}^{(0)}=T_{13+k} \quad k=27 \cdots 39
$$

and after the first iteration they take the values of $T_{k}^{(1)}, k=$ $27 \cdots 39$. The iterative algorithm continues until the following condition is satisfied:

$$
\left|\frac{T_{k}^{(n+1)}-T_{k}^{(n)}}{T_{k}^{(n+1)}}\right| \leq \varepsilon, \quad n=0,1,2, \ldots, k=27 \cdots 39
$$

Each of the calculated temperature histories can also be determined independently.

Once the temperature values in nodes 27 to 39 are obtained, an inverse solution can be run again to find the temperatures in points 14 to 26 by writing the heat balance equations for the control volumes associated with nodes 27 to 39 :

$$
\begin{aligned}
\frac{d T_{i}}{d t} & =\frac{4 a_{i}}{\left(r_{6}^{2}-r_{4}^{2}\right) \cdot \Delta \varphi}\left[\frac{k_{i+1}+k_{i}}{2 k_{i}} \cdot \frac{\Delta r}{r_{5} \cdot \Delta \varphi}\left(T_{i+1}-T_{i}\right)\right. \\
& +\frac{k_{i-13}+k_{i}}{2 k_{i}} \cdot \frac{r_{4} \cdot 0.5 \cdot \Delta \varphi}{\Delta r}\left(T_{i-13}-T_{i}\right)+\frac{k_{i+13}+k_{i}}{2 k_{i}} \\
& \left.\cdot \frac{r_{6} \cdot 0.5 \cdot \Delta \varphi}{\Delta r}\left(T_{i+13}-T_{i}\right)\right] \quad \text { for } i=27, \\
\frac{d T_{i}}{d t} & =\frac{2 a_{i}}{\left(r_{6}^{2}-r_{4}^{2}\right) \cdot \Delta \varphi}\left[\frac{k_{i-1}+k_{i}}{2 k_{i}} \cdot \frac{\Delta r}{r_{5} \cdot \Delta \varphi}\left(T_{i-1}-T_{i}\right)\right. \\
& +\frac{k_{i-13}+k_{i}}{2 k_{i}} \cdot \frac{r_{4} \cdot \Delta \varphi}{\Delta r}\left(T_{i-13}-T_{i}\right)+\frac{k_{i+1}+k_{i}}{2 k_{i}} \\
& \cdot \frac{\Delta r}{r_{5} \cdot \Delta \varphi}\left(T_{i+1}-T_{i}\right)+\frac{k_{i+13}+k_{i}}{2 k_{i}} \\
& \left.\cdot \frac{r_{6} \cdot \Delta \varphi}{\Delta r}\left(T_{i+13}-T_{i}\right)\right] \text { for } i=28 \cdots 38, \\
& \left.\frac{r_{6} \cdot 0.5 \cdot \Delta \varphi}{\Delta r}\left(T_{i+13}-T_{i}\right)\right] \quad \text { for } i=39 . \\
\frac{d T_{i}}{d t} & =\frac{4 a_{i}}{\left(r_{6}^{2}-r_{4}^{2}\right) \cdot \Delta \varphi}\left[\frac{k_{i-1}+k_{i}}{2 k_{i}} \cdot \frac{\Delta r}{r_{5} \cdot \Delta \varphi}\left(T_{i-1}-T_{i}\right)\right. \\
& \frac{k_{i} \cdot 0.5 \cdot \Delta \varphi}{\Delta r}\left(T_{i-13}-T_{i}\right)+\frac{k_{i+13}+k_{i}}{2 k_{i}}
\end{aligned}
$$

A similar system of equations can be written for volumes 14 to 26 to calculate temperature histories from nodes 1 to 13 . Next, the temperature distribution in every time step is used to conduct a structural analysis. The aim of the monitoring algorithm is to reduce the highest stresses to allowable values. This restriction can be captured by a simple structural analysis based on elementary equations of thermoelasticity (the force equilibrium equation, the geometric equation, and the constitutive equation):

$$
\begin{aligned}
\sigma_{i j, j}+f_{i} & =0 \\
\varepsilon_{i j} & =\frac{1}{2}\left(u_{i, j}+u_{j, i}\right), \\
\sigma_{i j} & =2 G \varepsilon_{i j}+\lambda \varepsilon_{k k} \delta_{i j}-\beta T \delta_{i j},
\end{aligned}
$$

where $\sigma$ is a stress tensor, $\mathbf{f}$ is the body forces vector, $\mathbf{u}$ is a displacement vector, $\varepsilon$ is a strain tensor, $G$ and $\lambda$ are Lame constants, $\beta$ is a thermal expansion coefficient, and $\delta_{i j}$ is the Kronecker delta [11].

There are two types of boundary conditions defined by displacement or force. The finite element method is used to discretize the above equations. The structural numerical model is presented in Figure 2. All inner surfaces of the header are loaded with internal pressure. One lateral surface of the chamber is loaded with longitudinal tension and the opposite lateral surface of the model is blocked at one point in the direction of the pipe axis. Additionally, the model is 


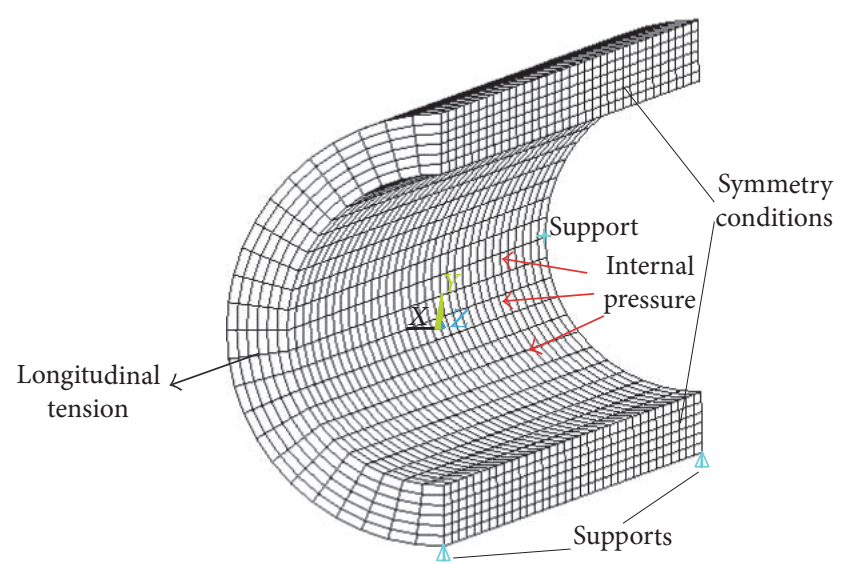

FIgURE 2: Structural model division into finite elements and assumed boundary conditions.

constrained to ensure symmetry conditions and is supported in two points in the direction of the vertical axis. Next, the calculated temperature distribution in every time step and in 52 points (see Figure 1) is approximated to 175 points on the cross-section of the model for the stress calculation (see Figure 2). Additionally, it is assumed that the same temperature distribution occurs in all other cross-sections of the model presented in Figure 2.

Solving inverse problems is more difficult compared to direct ones because inverse problems are ill-posed. The frequently observed oscillations in the solved transients can sometimes make the calculations completely unstable. There are many methods to solve this problem. One of them is to use smoothing filters to reduce the oscillations. The filters are based on local polynomial approximation (3rd-order kind and eleven subsequent measurement points) [7] and they smooth out the measured temperature curves.

\section{Temperature and Stress Monitoring in a Power Plant}

The presented method is used for temperature and stress monitoring in the outlet header of a steam reheater. The reheater is a component of a steam power boiler with the output of $650 \cdot 10^{3} \mathrm{~kg} / \mathrm{h}$ of steam characterized by the following parameters: $p=13.5 \mathrm{MPa}, T=540^{\circ} \mathrm{C}$. The reheater outlet header is designed for the working pressure of $p_{w}=$ $2.2 \mathrm{MPa}$ and the steam working temperature of $T_{w}=540^{\circ} \mathrm{C}$. It is made of $15 \mathrm{H} 1 \mathrm{MF}$ steel.

Figure 3 presents an example steam reheater outlet header which is used to collect or distribute generated steam. The part of the header without nozzles can be analysed by the model presented in Figure 2. Two horizontal nozzles can be seen in Figure 3. The component is also equipped with vertical nozzles.

The dimensions of the component are as follows: outer diameter $d_{o}=630 \mathrm{~mm}$, wall thickness $s=30 \mathrm{~mm}$, nozzle outer diameter $d_{\text {on }}=44.5 \mathrm{~mm}$, and nozzle wall thickness $s_{n}=4.5 \mathrm{~mm}$. Allowable stresses $\sigma_{\min }=-234.6 \mathrm{MPa}$ and $\sigma_{\max }=295.3 \mathrm{MPa}$ are determined using a fatigue strength diagram [12] under the assumption that the number of startups from a cold state is $n=2000$.

The temperature and stress distributions in the reheater outlet header are obtained based on temperature transients, which are measured in seven points on the outer insulated surface [13]. It is assumed that a cylindrical element can expand and bend freely.

Figure 4 presents the steam pressure and temperature transients measured in seven points on the header thermally insulated outer surface. The measured temperature transients are approximated to 13 points on the outer surface. Based on (5)-(10), the inverse method calculates the temperature transients in 52 points on the header cross-section presented in Figure 1. An in-house program was developed and applied in the data acquisition system presented in Figure 3. The temperature distribution is calculated by means of the controlvolume finite element method and the stress distribution by means of the finite element method.

The temperature transients calculated in seven points on the header inner surface are presented in Figure 5. After $500 \mathrm{~s}$ of the heating operation the temperature in point 1 drops to $148^{\circ} \mathrm{C}$, which is close to saturation temperature at the measured steam pressure of $0.32 \mathrm{MPa}$. At that instant, the temperature of the upper part of the steam header (points $7,9,11$, and 13) is considerably higher and the temperature difference between the lowest and the highest point on the inner surface equals $67^{\circ} \mathrm{C}$. This is most probably the effect of the flow of nonevaporated water from the reheater nondrained coil pipes to the reheater outlet header. The temperature differences recorded on the header circumference create thermal stresses, which are presented in Figures 6 and 7. As the reheated steam pressure is relatively low, the pressure-related stresses in the header are small. The highest absolute circumferential and longitudinal stresses are tensile and they occur in the header lower, colder part. They reach their highest value after $450 \mathrm{~s}$ of the heating period and total 53.6 $\mathrm{MPa}$ and $75.7 \mathrm{MPa}$, respectively. These values are about $30 \%$ lower than those presented in [13], which is due to the presented numerical model better accuracy compared to the method used in [13]. The number of finite volumes in the inverse solution is increased from 28 to 52 . The plane structural model with 52 nodes is upgraded to a $3 \mathrm{D}$ structural model with six elements on the wall thickness, 24 along the circumference and 34 along the horizontal axis. The longitudinal thermal stress distribution on the outlet header cross-section after $450 \mathrm{~s}$ of the heating operation is presented in Figure 8. The highest compressive circumferential and longitudinal stresses arise after $690 \mathrm{~s}$ of the heating period, totalling $-31.8 \mathrm{MPa}$ and $-40.2 \mathrm{MPa}$, respectively.

In order to estimate stresses arising on the downcomer hole edges, thermal stresses are calculated in a cylindrical component and in a cylindrical component weakened by a nozzle. Since the geometry of the header with one nozzle is symmetrical, $1 / 4$ of the construction element is modelled and analysed. The numerical model of a cylindrical element with a nozzle is presented in Figure 10. It is assumed that the outer surface of the two components with a uniform initial temperature $T_{0}=20^{\circ} \mathrm{C}$ is ideally insulated and that the 


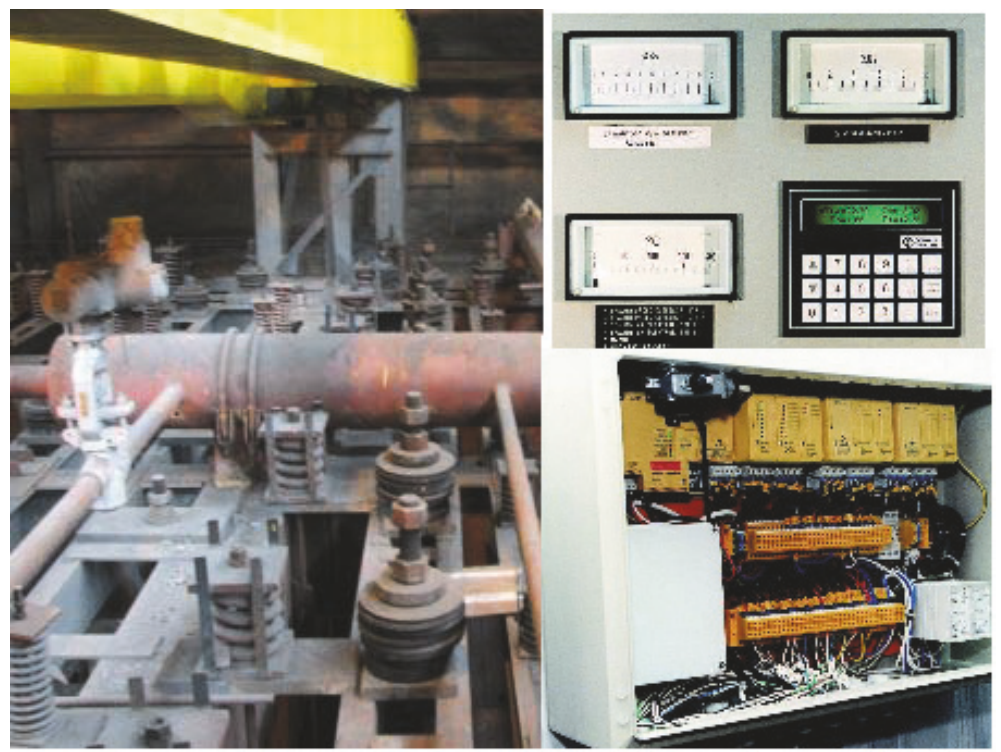

FigURE 3: The steam reheater outlet header and the control panel with the data acquisition system.

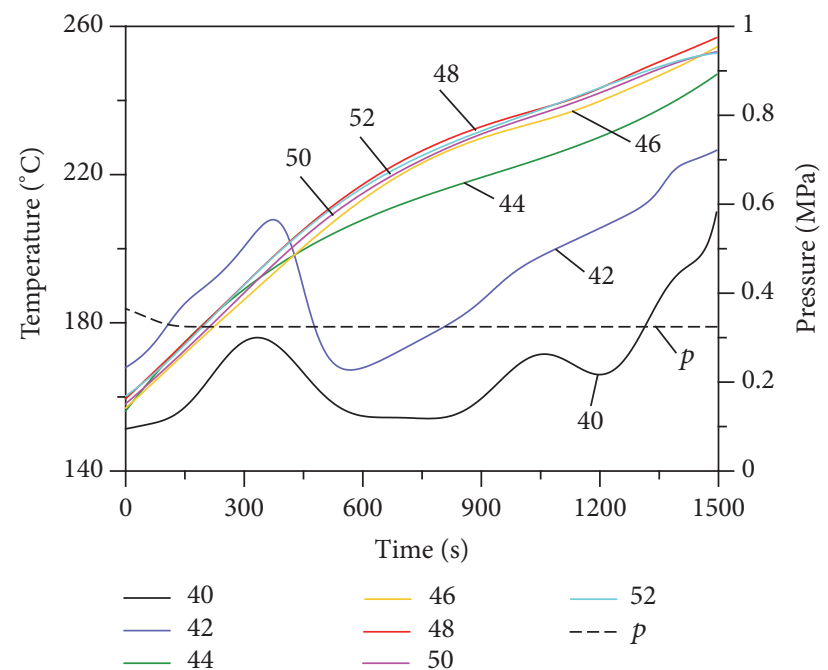

FIGURE 4: Measured steam pressure and temperature transients on the reheater outer header surface; nodes 44-52 are shown in Figure 1.

components are heated by steam on their inner surface. The steam temperature rises at a constant rate of $v_{t}=46.9 \mathrm{~K} / \mathrm{min}$.

Next, the model is constrained to ensure symmetry conditions and to allow for the possibility of free lengthening in the direction of the header and the nozzle axis. The temperature distribution in every time step is used for a structural analysis. The maximum compressive circumferential thermal stresses in a cylindrical component with and without a nozzle are presented in Figure 9. The thermal stress concentration factor $\alpha_{t}=2.05$ is calculated after $800 \mathrm{~s}$ of the heating process, when a quasi-steady-state occurs. The minimum and the maximum stress on the downcomer

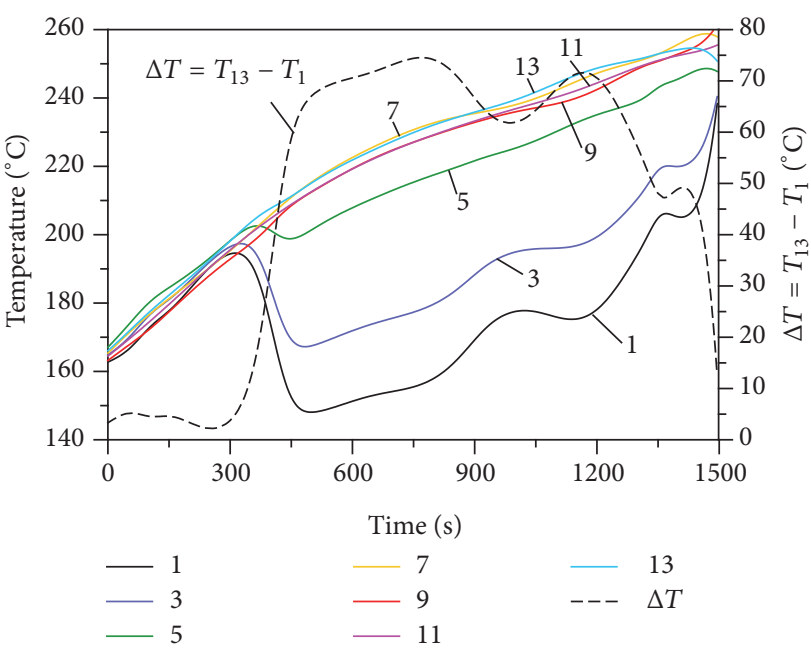

FIGURE 5: Temperature transients on the outlet header inner surface and the temperature difference transient between the outlet header top and bottom $\Delta T=T_{13}-T_{1}$.

hole edges can be estimated at $-82.4 \mathrm{MPa}$ and $155.2 \mathrm{MPa}$, respectively. The values do not exceed the allowable stresses $\sigma_{\text {min }}=-234.6 \mathrm{MPa}$ and $\sigma_{\max }=295.3 \mathrm{MPa}$.

If the presented heating process was shortened from $1500 \mathrm{~s}$ to $600 \mathrm{~s}$, the recorded stresses would be much higher. Figure 11 presents the longitudinal thermal stress transients in seven points on the outlet header inner surface when the heating operation is faster. The minimum and the maximum stress on the downcomer hole edges can be estimated at $-113.5 \mathrm{MPa}$ and $304.9 \mathrm{MPa}$, respectively. The maximum tensile thermal stress exceeds the allowable value. 


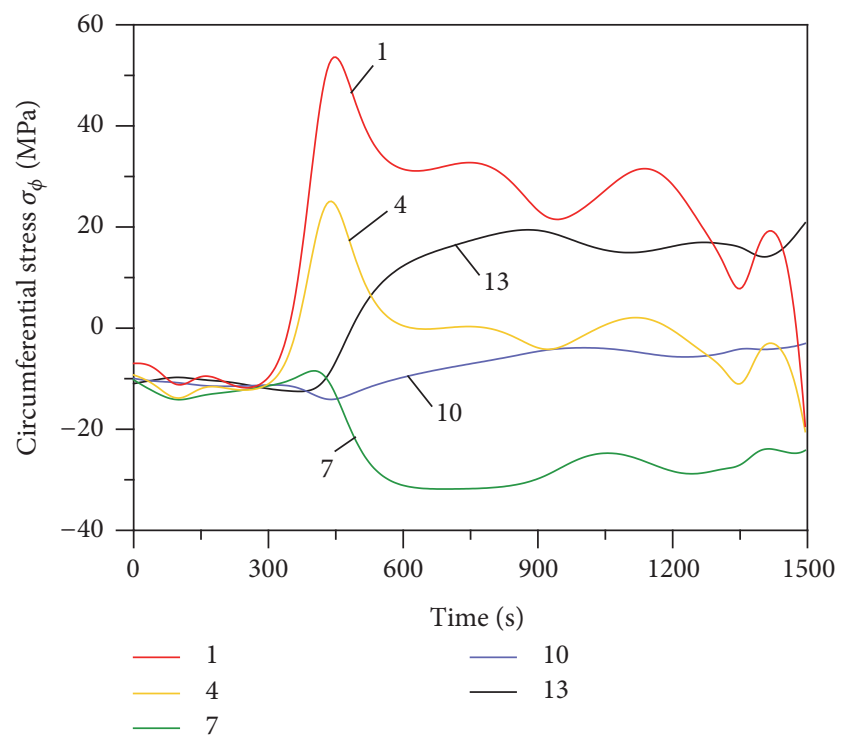

FIGURE 6: Circumferential thermal stress transients in seven points on the outlet header inner surface.

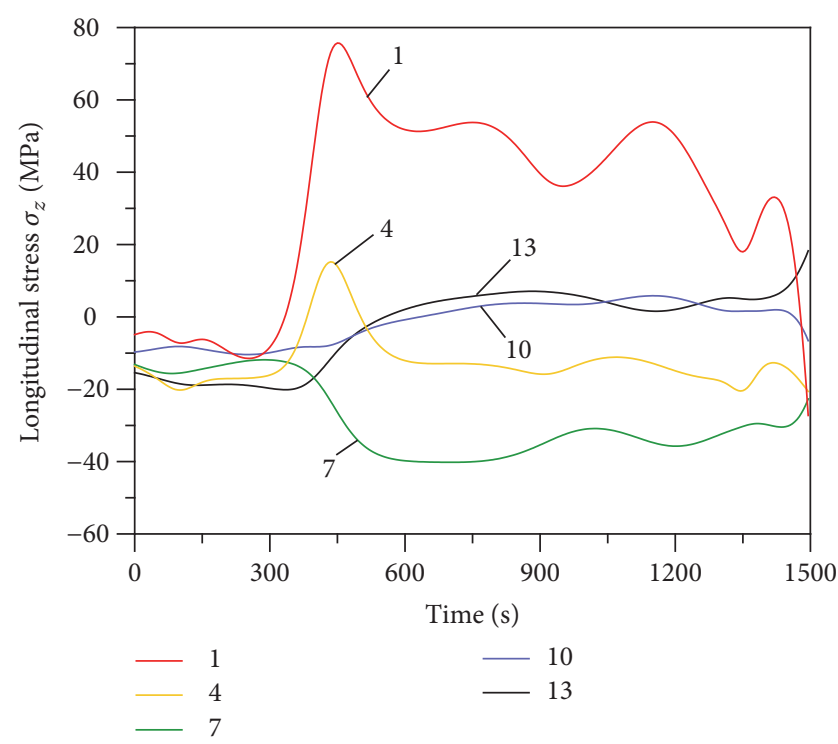

FIGURE 7: Longitudinal thermal stress transients in seven points on the outlet header inner surface.

\section{Conclusions}

The paper presents a method of temperature and stress estimation in pressure components of conventional or nuclear power plants. The proposed algorithm can be applied without the information concerning the thermal boundary condition on the component inner surfaces and it is fast enough to be applied in an online mode. The solution is possible thanks to "measured" temperature transients determined in easily accessible points located on the component outer surface. An application of the proposed algorithm for the calculation of the transient temperature and stress distribution in the steam reheater outlet header indicates that the component

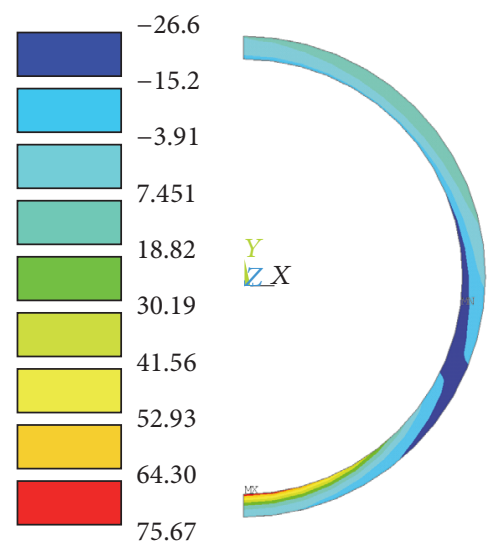

FIGURE 8: Longitudinal thermal stress distribution in the outlet header cross-section after $450 \mathrm{~s}[\mathrm{MPa}]$.

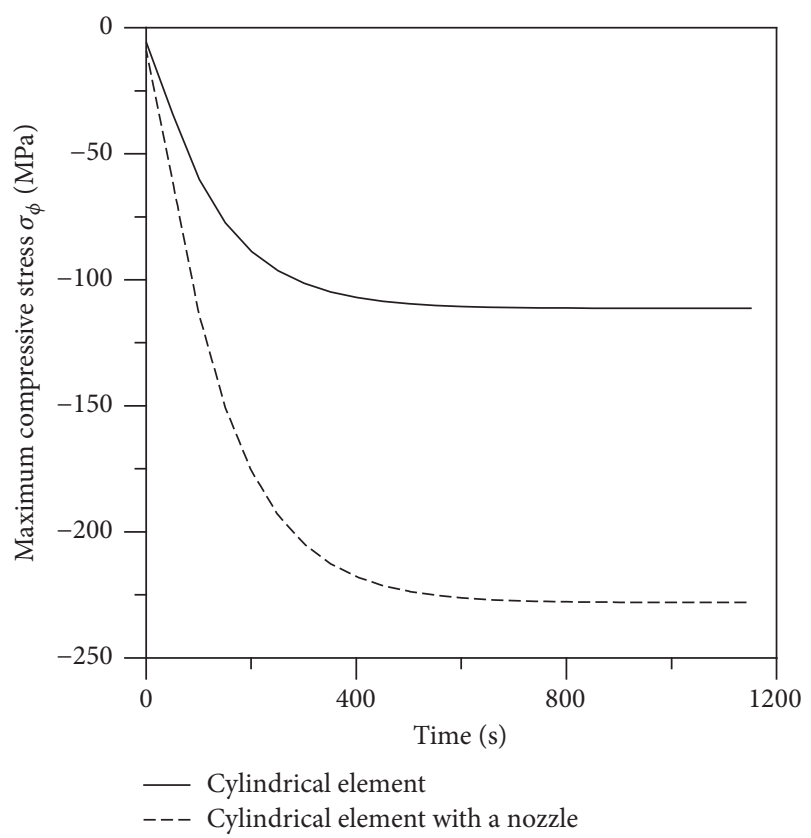

FIGURE 9: Maximum compressive circumferential thermal stress in a cylindrical component with and without a nozzle.

lower part is loaded the most. This is probably the effect of the flow of nonevaporated water, which did not leave the reheater through the coil draining pipes. The highest absolute stress is the tensile longitudinal stress. In order to estimate stresses on the hole edges, the thermal stress concentration factor is calculated. The minimum and the maximum stresses on the downcomer hole edges do not exceed the allowable values. Additionally, a modification of the presented process is assumed. If the heating process was shortened from $1500 \mathrm{~s}$ to $600 \mathrm{~s}$, the recorded tensile stress on the downcomer hole edges would exceed the allowable value.

Monitoring the boiler thermal and strength operating conditions makes it possible to identify dangerous loads of the power boiler pressure elements during transient-state operations. All the histories of stresses arising due to pressure 


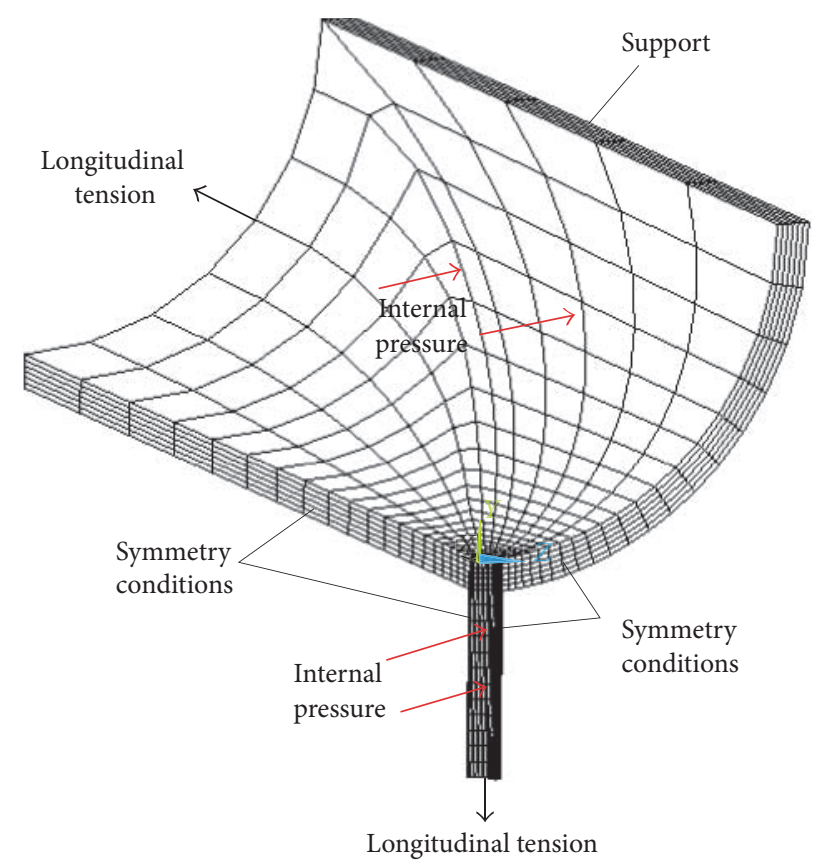

FIgure 10: Division of the model of a cylindrical element with a nozzle into finite elements and the assumed boundary conditions.

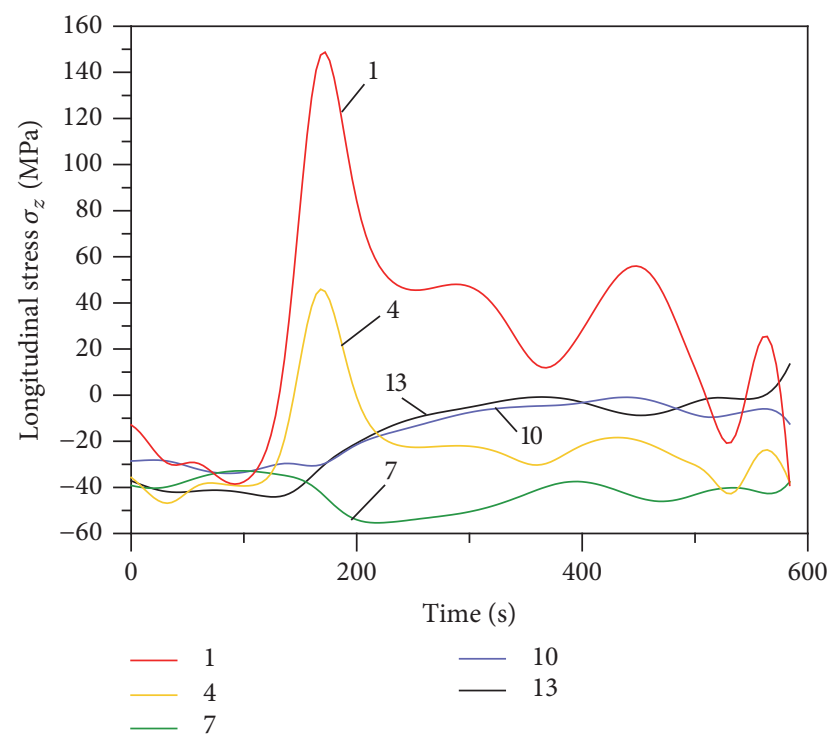

FIGURE 11: Longitudinal thermal stress transients in seven points on the outlet header inner surface during the faster heating process.

and thermal loads are the basis for determining the creep and fatigue wear factors for pressure components. The presented method for controlling thermal and pressure-related stresses is suitable for nuclear power plants because it does not require drilling holes for sensors in the pressure element walls.

\section{Conflicts of Interest}

The author declares that there are no conflicts of interest regarding the publication of this paper.

\section{Acknowledgments}

This research was financed by the National Science Centre, Poland, UMO-2015/19/B/ST8/00958.

\section{References}

[1] E. Roos, K.-H. Herter, X. Schuler, J. Chattopadhyay, and H. S. Kushwaha, "Integrity assessment for safety relevant nuclear piping," International Journal of Pressure Vessels and Piping, vol. 123, pp. 46-59, 2014.

[2] G. L. Stevens, D. A. Gerber, and S. T. Rosinski, "Latest advances in fatigue monitoring technology using EPRIs FatiguePro software," SMiRT, p. 15, 1999.

[3] H. Golembiewski and M. Miksch, "Fatigue monitoring in German nuclear power plants," in Proceedings of the SMiRT 11 Post-Conference Seminar, vol. 2, 1991.

[4] I. R. Paterson and J. D. Wilson, "Use of damage monitoring systems for component life optimisation in power plant," International Journal of Pressure Vessels and Piping, vol. 79, no. 8-10, pp. 541-547, 2002.

[5] M. J. Jhung, "Assessment of thermal fatigue in mixing tee by FSI analysis," Nuclear Engineering and Technology, vol. 45, no. 1, pp. 99-106, 2013.

[6] G.-H. Koo, J.-J. Kwon, and W. Kim, "Green's function method with consideration of temperature dependent material properties for fatigue monitoring of nuclear power plants," International Journal of Pressure Vessels and Piping, vol. 86, no. 2-3, pp. 187-195, 2009.

[7] P. Duda, "Solution of an inverse axisymmetric heat conduction problem in complicated geometry," International Journal of Heat and Mass Transfer, vol. 82, pp. 419-428, 2015.

[8] J. Taler and P. Duda, "Experimental verification of space marching methods for solving inverse heat conduction problems," Heat and Mass Transfer, vol. 36, no. 4, pp. 325-331, 2000.

[9] P. Duda, "Inverse estimation of the transient-state stress distribution in the power boiler pressure components," International Journal of Mechanical Sciences, vol. 107, pp. 201-214, 2016.

[10] B. R. Baliga and S. V. Patankar, "A control volume finite-element method for two-dimensional fluid flow and heat transfer," Numerical Heat Transfer, Part B: Fundamentals, vol. 6, no. 3, pp. 245-261, 1983.

[11] A. W. Ganczarski, H. Egner, A. Muc, and J. J. Skrzypek, "Constitutive models for analysis and design of multifunctional technological materials," in Innovative Technological Materials: Structural Properties by Neutron Scattering, Synchrotron Radiation and Modeling, F. Rustichelli and J. J. Skrzypek, Eds., pp. 179-223, Springer, 2010.

[12] TRD 301, Technische Regeln für Dampfkessel, Carl Heymans Verlag, Köln und Beuth-Verlag, Berlin, Germany, 2001.

[13] B. Weglowski, J. Taler, and P. Duda, "Monitoring of Thermal Stresses in Steam Generators," in Proceedings of the 17th International Conference on Structural Mechanics in Reactor Technology (SmiRT 17), vol. 8, Prague, Czech Republic, 2003. 


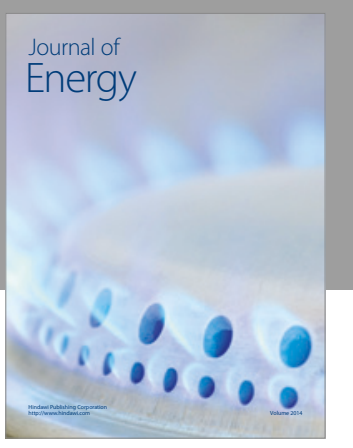

Journal of

Industrial Engineering
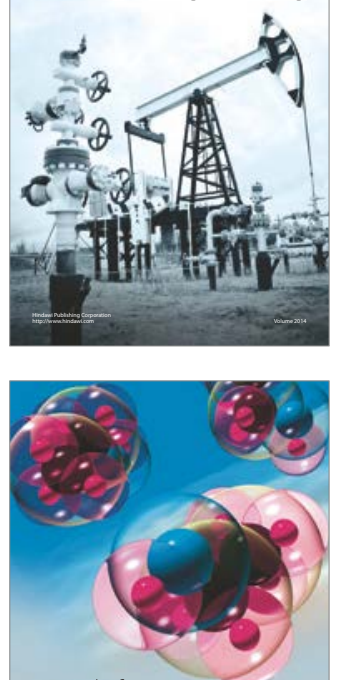

Fuels
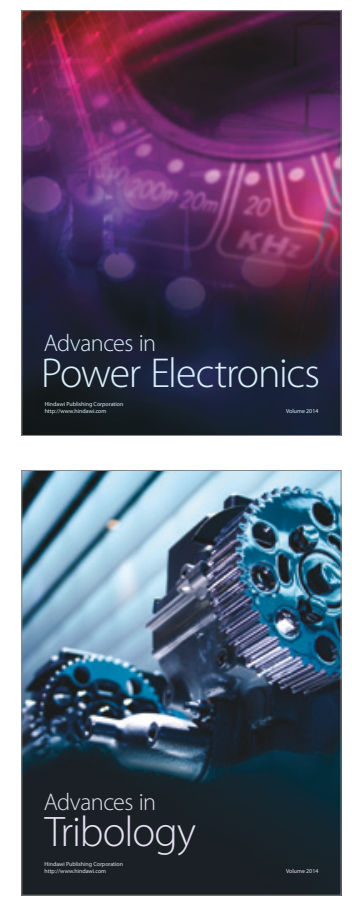
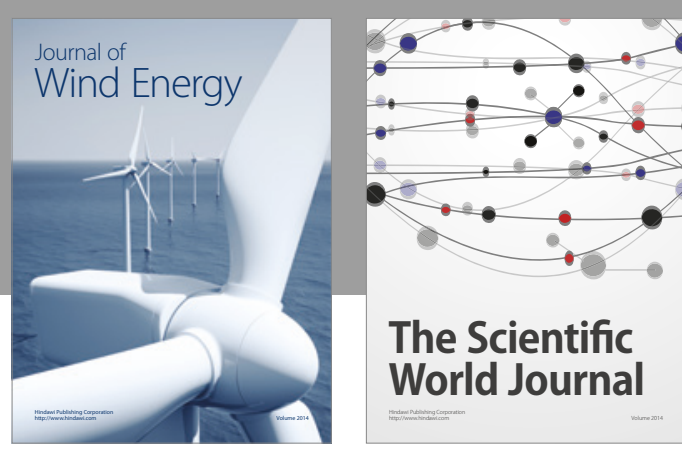

The Scientific World Journal
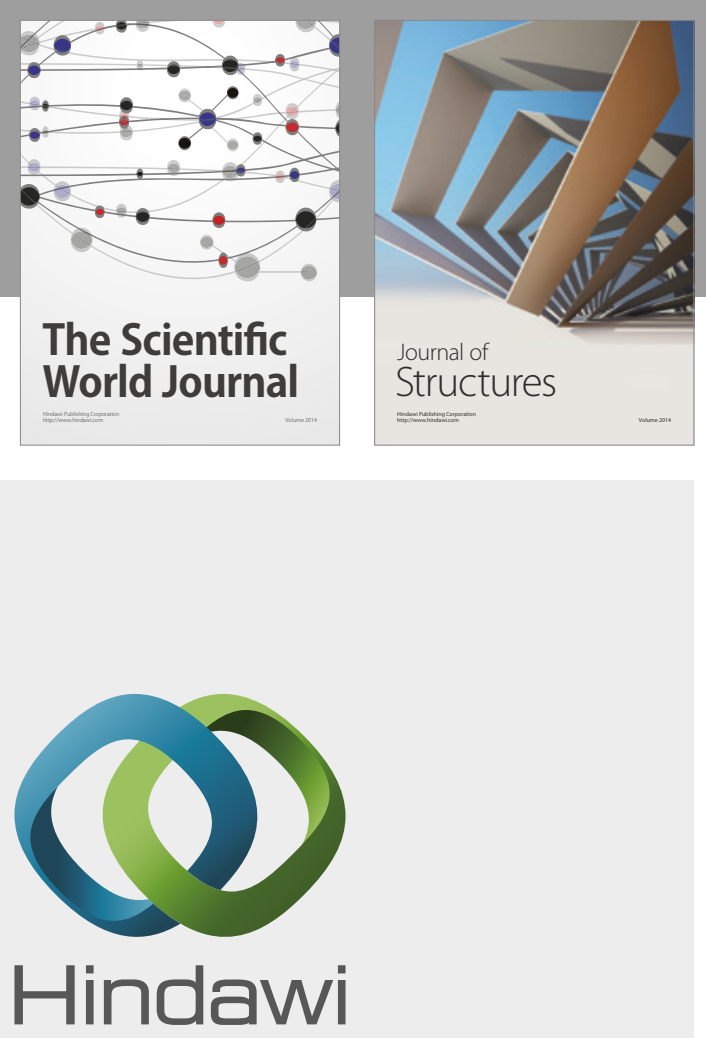

Submit your manuscripts at

https://www.hindawi.com
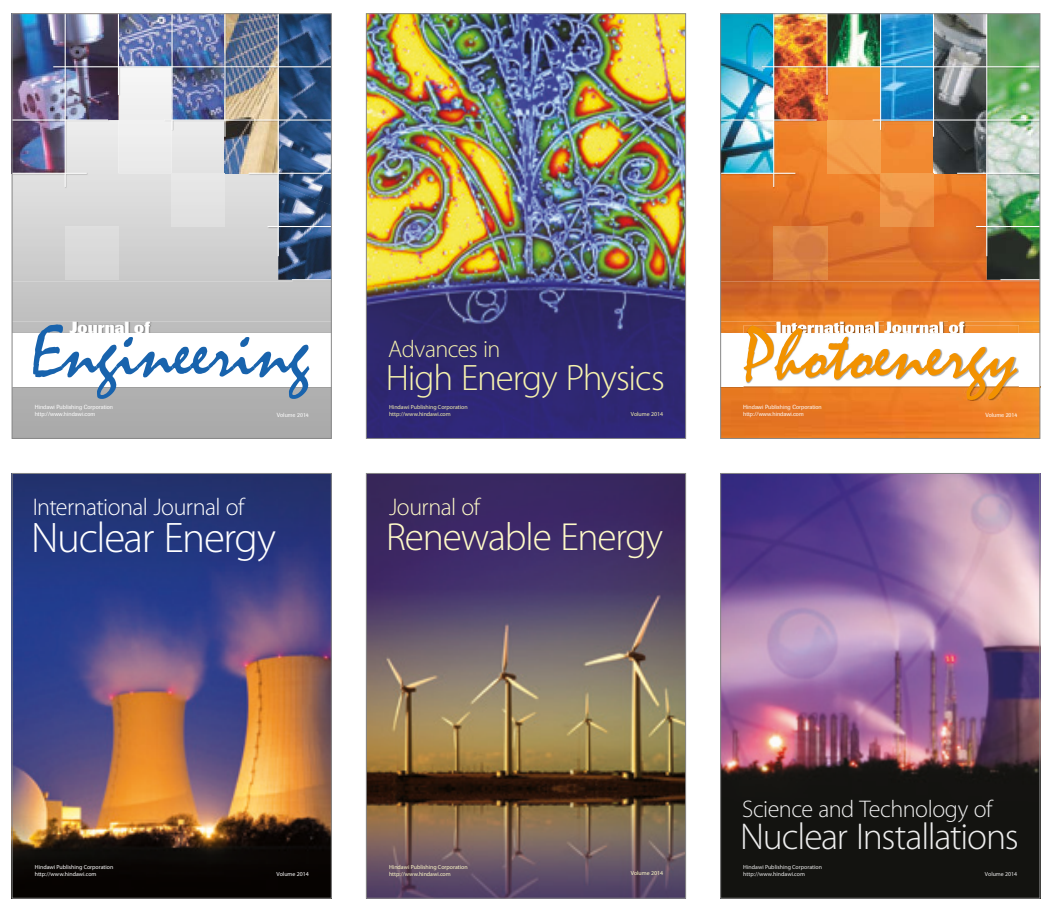

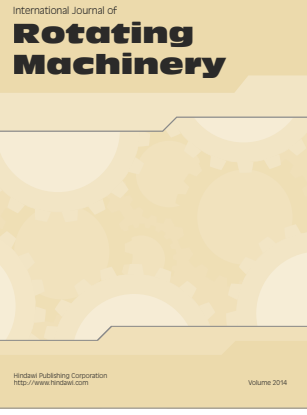

Journal of

Petroleum Engineering

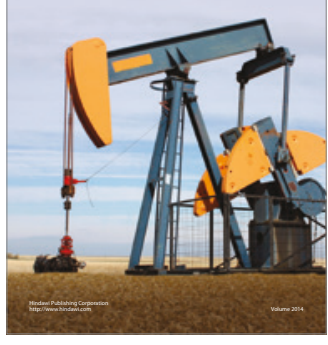

Journal of
Solar Energy
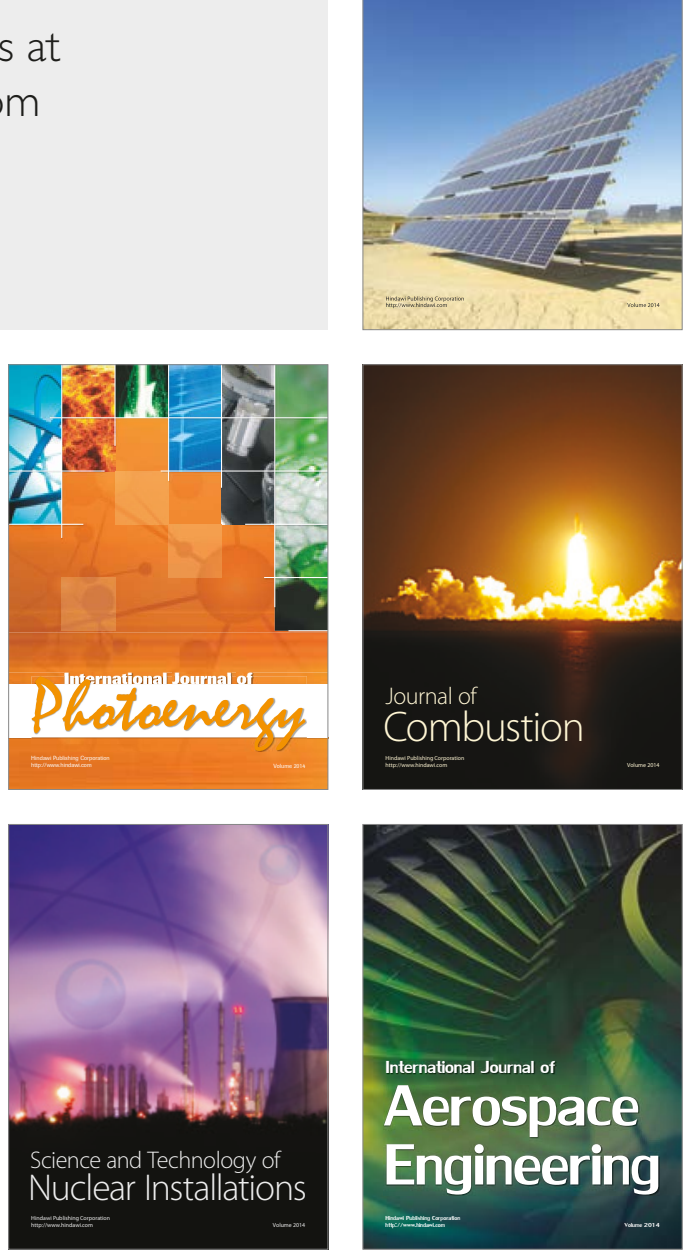